\title{
Correction to: Exploring object-based content adaptation for mobile audio
}

\author{
Tim Walton ${ }^{1} \cdot$ Michael Evans $^{2} \cdot$ David Kirk $^{3} \cdot$ Frank Melchior $^{2}$
}

Published online: 21 April 2018

(C) Springer-Verlag London Ltd., part of Springer Nature 2018

\section{Correction to: Pers Ubiquit Comput https://doi.org/10.1007/s00779-018-1125-6}

Due to miscommunication in the typesetting process, the following $\mathrm{p}$ values in "Exploring object-based content adaptation for mobile audio" require correction:

Section 3.2.1, line $9, \mathrm{p}=<.000$ should read $\mathrm{p}<.001$

Section 3.2.1, line 10, $\mathrm{p}=<.001$ should read $\mathrm{p}<.001$

Section 3.2.1, line 11, $\mathrm{p}<0.5$ should read $\mathrm{p}<.05$

Section 3.2.2, line $3, p=<.001$ should read $p<.001$

The original article has been corrected.

The online version of the original article can be found at https://doi.org/ 10.1007/s00779-018-1125-6

\footnotetext{
Tim Walton

t.walton3@ncl.ac.uk

1 Open Lab, Newcastle University, Newcastle upon Tyne, UK

2 BBC Research and Development, Salford, UK

3 Northumbria University, Newcastle upon Tyne, UK
} 